\title{
Comparisons between field- and LiDAR-based measures of stand structural complexity
}

\author{
Van R. Kane, Robert J. McGaughey, Jonathan D. Bakker, Rolf F. Gersonde, \\ James A. Lutz, and Jerry F. Franklin
}

\begin{abstract}
Forest structure, as measured by the physical arrangement of trees and their crowns, is a fundamental attribute of forest ecosystems that changes as forests progress through suc;cessional stages. We examined whether LiDAR data could be used to directly assess the successional stage of forests by determining the degree to which the LiDAR data would show the same relative ranking of structural development among sites as would traditional field measurements. We sampled 94 primary and secondary sites (19-93, 223-350, and 600 years old) from three conifer forest zones in western Washington state, USA, in the field and with small-footprint, discrete return LiDAR. Seven sets of LiDAR metrics were tested to measure canopy structure. Ordinations using the of LiDAR 95th percentile height, rumple, and canopy density metrics had the strongest correlations with ordinations using two sets of field metrics (Procrustes $R=0.72$ and 0.78 ) and a combined set of LiDAR and field metrics (Procrustes $R=0.95$ ). These results suggest that LiDAR can accurately characterize forest successional stage where field measurements are not available. This has important implications for enabling basic and applied studies of forest structure at stand to landscape scales.
\end{abstract}

\begin{abstract}
Résumé : La structure de la forêt, telle qu'elle est mesurée par la disposition physique des arbres et de leur cime, est un attribut fondamental des écosystèmes forestiers qui change à mesure que les forêts passent à travers les stades de succession. Nous avons examiné si les données obtenus avec le LiDAR pouvaient être utilisées pour évaluer directement le stade de succession en déterminant dans quelle mesure les données LiDAR produisent le même classement relatif du développement structural de différentes stations que les mesures traditionnelles prises sur le terrain. Nous avons échantillonné 94 stations dans des forêts vierges et de seconde venue (âgées de 19 à 93, 223 à 350 et 600 ans) sur le terrain et avec un LiDAR à impulsions discrètes et petite empreinte. L'étude a été réalisée dans trois régions couvertes de forêt résineuse dans l'ouest de l'État de Washington, aux États-Unis. Sept séries de mesures obtenues avec le LiDAR ont été testées pour mesurer la structure du couvert. Les ordinations utilisant les mesures du $95^{\text {ième }}$ percentile de la hauteur, du plissement et de la densité du couvert provenant du LiDAR avaient les plus fortes corrélations avec les ordinations utilisant deux séries de mesures prises sur le terrain (Procrustes $R=0,72$ et 0,78 ) et une série de mesures provenant du LiDAR et de mesures prises sur le terrain combinées (Procrustes $R=0,95$ ). Ces résultats indiquent que le LiDAR peut caractériser avec exactitude le stade de succession de la forêt lorsque les données terrain ne sont pas disponibles. Cela a d'importantes répercussions pour permettre la réalisation de travaux de recherche fondamentale et appliquée sur la structure de la forêt en allant de l'échelle du peuplement à l'échelle du paysage.
\end{abstract}

[Traduit par la Rédaction]

\section{Introduction}

The three-dimensional arrangement of trees and their crowns is a fundamental attribute of forest ecosystems that correlates strongly with many ecological processes and services, including biological diversity (McElhinny et al. 2005). Forest structure has many components but is often described by the size and spatial distribution of trees and by the horizontal and vertical distribution of their foliage (Spies 1998; Van Pelt and Nadkarni 2004; McElhinny et al. 2005). These components often change as stands mature as do other aspects of forest structure and diversity that are directly or in- directly related to the size and spatial distribution of trees such as coarse woody debris, dead trees, abundance and diversity of the understory, and seral tree regeneration and biodiversity (Franklin and Spies 1991; Lindenmayer and Franklin 2002).

Because of the strong allometric relationships between canopies and other aspects of stand structure, LiDAR measurements have been shown to produce more accurate estimates of parameters such as mean tree diameter, basal area, biomass, and height than other remote sensing options (Lefsky et al. 2001). Researchers have used LiDAR data to measure crown height and length (Næsset and Okland 2002)

Received 3 August 2009. Accepted 11 January 2010. Published on the NRC Research Press Web site at cjfr.nrc.ca on 16 April 2010.

V.R. Kane, ${ }^{1}$ J.D. Bakker, J.A. Lutz, and J.F. Franklin. School of Forest Resources, College of the Environment, University of Washington, Box 352100, Seattle, WA 98195, USA.

R.J. McGaughey. Pacific Northwest Research Station, USDA Forest Service, University of Washington, Box 352100, Seattle, WA 98195, USA.

R.F. Gersonde. Watershed Services Division, Seattle Public Utilities, 19901 Cedar Falls Road SE, North Bend, WA 98045, USA.

${ }^{1}$ Corresponding author (e-mail: vkane@u.washington.edu). 
and to estimate variation in tree diameter, tree density, and basal area (Lefsky et al. 1999), aboveground biomass (Lefsky et al. 2002), and fuel loads (Skowronski et al. 2007).

The ability to map the structural stage of forests across landscapes using LiDAR data would be useful to researchers studying forest structure and function, biologists mapping potential habitat, and managers seeking to inventory their properties. Several researchers have found that canopies representing different stages within a successional trajectory have distinct characteristics when measured with LiDAR, including tulip popular deciduous forests (Harding et al. 2001; Parker and Russ 2004) and Pacific Northwest conifer forests (Lefsky et al. 1999). Hill and Thomson (2005) used LiDAR and hyperspectral data to map different stages of forest succession in England. Falkowski et al. (2009) used LiDAR data to successfully predict forest successional stage using six categorical stages previously defined from field data for Rocky Mountain forests with a 95.5\% accuracy rate. This latter work demonstrates the potential of LiDAR to provide forest classifications that would be immediately interpretable and usable by a wide variety of forest professionals.

These previous studies examined the ability of LiDAR data to distinguish between distinct successional stages. However, forest succession can be thought of as a continuous process that produces gradients of structural characteristics rather than distinct classes of structure. Our study examines the ability of LiDAR data to measure succession along gradients of multiple structural characteristics. Demonstrating this ability would provide the theoretical basis for classifying succession with LiDAR data. It would also provide an alternative method for measuring succession to the imputation method used by Falkowski et al. (2009). This would be useful either where adequate successional classification schemes do not exist or when researchers want to test the comprehensiveness of existing classification schemes (e.g., Kane et al. 2010).

No single field or LiDAR measurement captures the state of a stand's structural development. Instead, studying patterns of development requires examining relative changes in suites of metrics, often using multivariate analyses such as ordinations (Spies and Franklin 1991; Larson et al. 2008). For example, four field variables (mean diameter at breast height $(\mathrm{DBH})$, standard deviation of $\mathrm{DBH}$, tree density, and density of trees with $\mathrm{DBH}>100 \mathrm{~cm}$ ) are strongly correlated with the structural stage in Pacific Northwest forests (Spies and Franklin 1991) and can be used to estimate the degree to which a stand has progressed toward old-growth characteristics (Acker et al. 1998). Subsequent work has emphasized the importance of the number and size of canopy gaps as a measure of structural state (Spies 1998; Van Pelt and Franklin 2000). Lefsky et al. (2005) found that a combination of three LiDAR metrics (mean height of LiDAR returns, standard deviation of LiDAR returns, and canopy closure) closely correlate with field measurements of structural attributes.

Our goal in this study was to examine whether LiDAR data could be used to directly assess the relative successional stage of forests using plots spanning a range of ages and forest zones in the conifer forests of the Pacific North- west, USA We pursued this goal through three specific objectives.

The first objective was to determine the degree to which LiDAR metrics would show the same relative ranking of structural development among sites as would traditional field measurements. Previous work had established that canopy structural complexity increases during forest structural development as measured by increased crown height, crown surface roughness (rumple), and canopy gaps (Van Pelt and Franklin 2000; Ishii and McDowell 2002; Van Pelt and Nadkarni 2004; Ogunjemiyo et al. 2005; Kane et al. 2008; Van Pelt and Sillett 2008). These characteristics can be easily measured with LiDAR. We assessed correlation between field and LiDAR assessments of structural development by quantitatively comparing ordinations using both types of data. If the ordinations were highly correlated, this would provide a basis for mapping the successional stages directly from LiDAR data alone.

The second objective was to determine whether a small set of easily interpreted LiDAR metrics could be used to differentiate sites based on their relative structural complexity. This objective paralleled the work of Lefsky et al. (2005), who examined this question using LiDAR data from an experimental large-footprint, waveform instrument. Because most LiDAR acquisitions use small-footprint, discrete return instruments, their results should be validated using this more common data type. The identification of such a subset could make maps of forest structure easier to interpret by a variety of forest professionals.

A third objective was to determine the effect of using a fixed-sized LiDAR sample area when our field data were collected over variable plot sizes. While variable-sized field plots are common in many studies, fixed-grid cells are used to create maps from remote sensing data sets. We calculated our LiDAR metrics using both fixed-sized areas and variable-sized areas that matched the variable field plot areas. It was presumed that LiDAR data calculated from areas the same size as the underlying plots would be more strongly correlated with field measurements than would those from the fixed grid size.

\section{Methods}

\section{Structural characteristics measured}

We selected five field and six LiDAR metrics that had been identified in other studies as key for distinguishing forest structural condition (Table 1). Data for example plots are presented in Fig. 1 and Table 2.

Four field metrics were based on key live tree structural attributes identified by Spies and Franklin (1991): mean $\mathrm{DBH}$, standard deviation (SD) of $\mathrm{DBH}$, density of trees per hectare, and density of trees with $\mathrm{DBH}>100 \mathrm{~cm}$. Canopy cover was selected as a fifth field metric because of its importance as an indicator of disturbance and availability of light to lower canopy layers and the understory (Spies 1998; Van Pelt and Franklin 2000).

The LiDAR metrics were selected from three categories of metrics found by Lefsky et al. (2005) to be highly correlated with field measurements of stand structure: height, variation of height, and canopy density (which is a LiDAR measure of canopy closure). We tested their suggested Li- 
Table 1. Field- and LiDAR-based metrics used in the study.

\begin{tabular}{|c|c|}
\hline & Notes \\
\hline \multicolumn{2}{|l|}{ Field-based metrics } \\
\hline \multicolumn{2}{|l|}{ Mean DBH } \\
\hline \multicolumn{2}{|l|}{ SD DBH } \\
\hline \multicolumn{2}{|l|}{$\begin{array}{l}\text { Density of trees }>100 \mathrm{~cm} \text { DBH per hec- } \\
\text { tare }\end{array}$} \\
\hline Canopy cover & Canopy closure (proportion). Averaged from 16 measurements with a spherical densiometer \\
\hline 95th percentile height of first returns $(\mathrm{m})$ & Similar to maximum height but less sensitive to anomalously high points \\
\hline Mean height of first returns (m) & Sensitive to tree height and to changes in distribution of foliage along the stem \\
\hline SD first return heights & Sensitive only to vertical variation in canopy structure \\
\hline CV first return heights & Sensitive only to vertical variation in canopy structure \\
\hline Rumple index & $\begin{array}{l}\text { Ratio of three-dimensional canopy surface model area to ground area. Calculated by sum- } \\
\text { ming the three-dimensional area of triangles formed by canopy surface model grid points } \\
\text { divided by the two-dimensional area of the grid cell surface. Sensitive to vertical and hor- } \\
\text { izontal variation in canopy structure }\end{array}$ \\
\hline
\end{tabular}

Note: See Methods for details on metrics and basis for selection.

Fig. 1. Examples of the range of canopies for plots used in this study. Each canopy surface shown was created for one of the plots from the LiDAR data $(30 \mathrm{~m} \times 30 \mathrm{~m}$ areas). Canopies were considered to be more structurally complex as crown heights and rumple values increase and as canopy densities (proportion of canopy with foliage blocking view of the ground from the LiDAR instrument) decrease through the formation of gaps. Table 2 provides measured field and LiDAR metric values for these example plots.

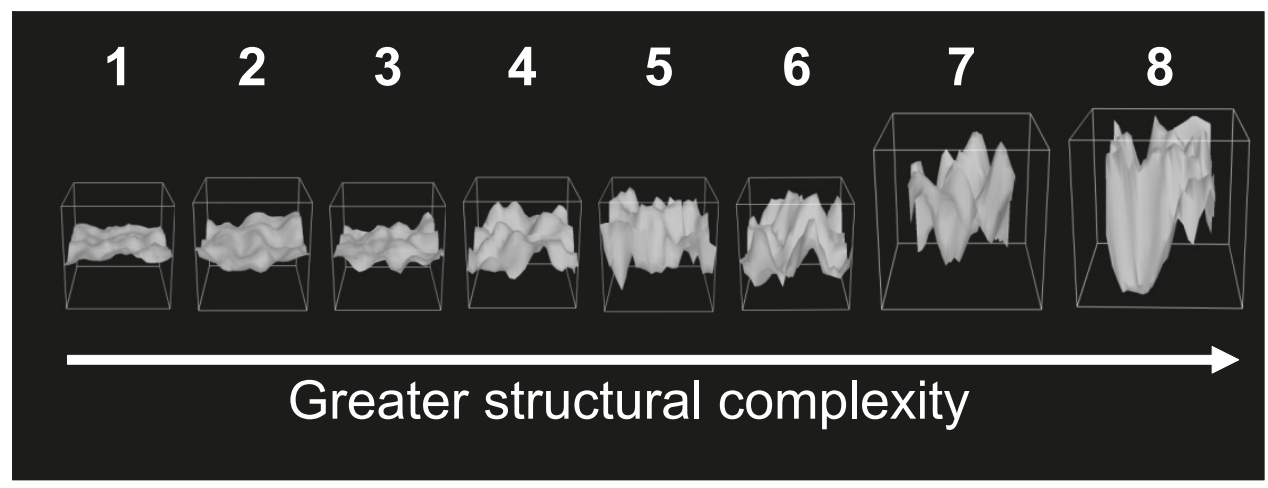

DAR metrics (mean height, SD of height, and canopy density) along with the 95th percentile of height, coefficient of variation $(\mathrm{CV})$ of height, and rumple. Rumple is the ratio of canopy outer surface area to ground surface area (Parker et al. 2004) as measured by the LiDAR-derived canopy surface model and digital terrain model (see "LiDAR data" below). It is therefore a three-dimensional measure of canopy structural heterogeneity, whereas SD and CV of height are onedimensional measures (Fig. 2).

There are fundamental differences between field- and LiDAR-derived measurements of height. For example, fieldmeasured "mean height" typically refers to the mean of the maxima for individual treetops in field measurements. LiDAR-measured "mean height" refers to the mean of all returns along the exposed crown surfaces and understory and ground, where visible to the instrument. The 95th percentile LiDAR height measurement used in this study is the height at which $95 \%$ of LiDAR returns fall below. This measurement is likely closely aligned with field-measured mean height of canopy maxima.
Since we used only first return LiDAR data (see below), it is likely that most of our measurements represent the upper canopy. The number of returns from the subcanopy was insufficient to draw any conclusions regarding structure at this level.

\section{Study area}

The 36679 ha Cedar River Municipal Watershed is located on the western slope of Cascade Range in Washington State, USA (Fig. 3). Elevations range from 165 to $1655 \mathrm{~m}$. Forests at elevations below $\sim 800 \mathrm{~m}$ lie in the Western Hemlock Zone (Henderson et al. 1992; Franklin and Dyrness 1988). Elevations from $\sim 800$ to $1200 \mathrm{~m}$ lie in the Pacific Silver Fir Zone. Forests above $\sim 1200 \mathrm{~m}$ lie in the Mountain Hemlock Zone.

It is believed that the three forest zones follow similar sequences of structural development following stand-replacing disturbance (Franklin and Spies 1991; Larson and Franklin 2006; Parish and Antos 2006). Early seral stands in the Western Hemlock Zone typically are dominated by Pseudot- 


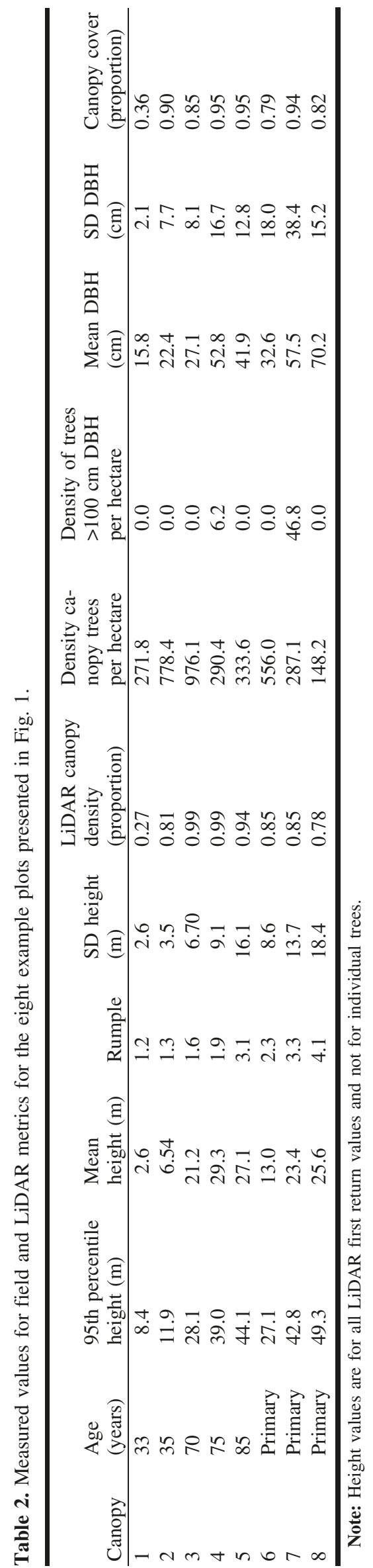

Fig. 2. Comparison of rumple index (ratio of canopy outer surface area to ground surface area) and standard deviation of height as measures of canopy structural complexity. Higher rumple values result from more heterogeneous three-dimensional vertical and horizontal heterogeneity, while standard deviation of height measures one-dimensional vertical heterogeneity. In both artificial canopy surface models, half of the points are at a height of $50 \mathrm{~m}$ and half are at $100 \mathrm{~m}$. Of the LiDAR metrics used in this study, only rumple would distinguish between these two surfaces.

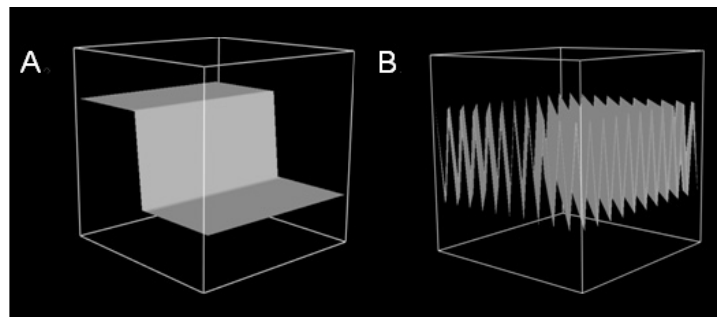

\begin{tabular}{lcc}
\hline & Surface A & Surface B \\
\hline Rumple & 1.4 & 14.2 \\
95th p. height & 100 & 100 \\
Mean height & 75 & 75 \\
SD height & 25 & 25 \\
\hline
\end{tabular}

suga menziesii ((Mirb.) Franco var. menziesii (Douglas-fir)), especially following harvest. Thuja plicata Donn ex D. Don (western redcedar) and Tsuga heterophylla (Raf.) Sarg. (western hemlock) are often early or later seral components. Forests in the Pacific Silver Fir Zone are primarily composed of shade-tolerant species Abies amabilis (Dougl. ex Loud.) Dougl. ex J. Forbes (Pacific silver fir) and T. heterophylla (Lertzman and Krebs 1991), with some early seral stands dominated by Abies procera Rehd. (noble fir). Stands in the Mountain Hemlock are often dominated by A. amabilis mixed with Tsuga mertensiana (Bong.) Carrière (mountain hemlock). Mature trees in the Pacific Silver Fir and Mountain Hemlock Zones generally do not reach the same heights and crown dimensions as comparable species in the Weatern Hemlock Zone.

The time scales for structural development differ in the three zones, with development slowing with increasing elevation. Competitive exclusion in the Western Hemlock Zone, for example, commonly lasts for 50 years (Franklin et al. 2002), for 100-300 years in the Pacific Silver Fir Zone (Packee et al. 1982), and for centuries in the Mountain Hemlock Zone (Parish and Antos 2006).

The majority of the watershed's forests (84\%) are second growth $(<100$ years old) that established naturally (pre1920s) or were planted following harvest (starting in the 1920s) (Erckmann et al. 2000). Timber harvests began in the western lowlands of the watershed in the early 20th century and moved eastward to higher elevations until harvest ceased in the 1990s. As a result, the ages of second-growth stands are correlated with elevation and forest zone. Less than $1 \%$ of the watershed was 100-200 years old; no stands in that age range were included in this study. A portion of the watershed (16\%), primarily at mid- to high elevations, consists of primary forests 200-350 years old that appear to 
Fig. 3. Shaded relief map of the Cedar River Municipal Watershed in Washington State, USA $\left(47.4^{\circ} \mathrm{N}, 121.9^{\circ} \mathrm{W}\right)$, showing dominant forest zones and plots. Plots shown by age classes based on development stages from Franklin et al. (2002) based on typical ages for the Western Hemlock Zone. Biomass accumulation/competitive exclusion class is shown as two age classes because of the large number of plots sites in this developmental stage. Insert shows Watershed location within Washington State.

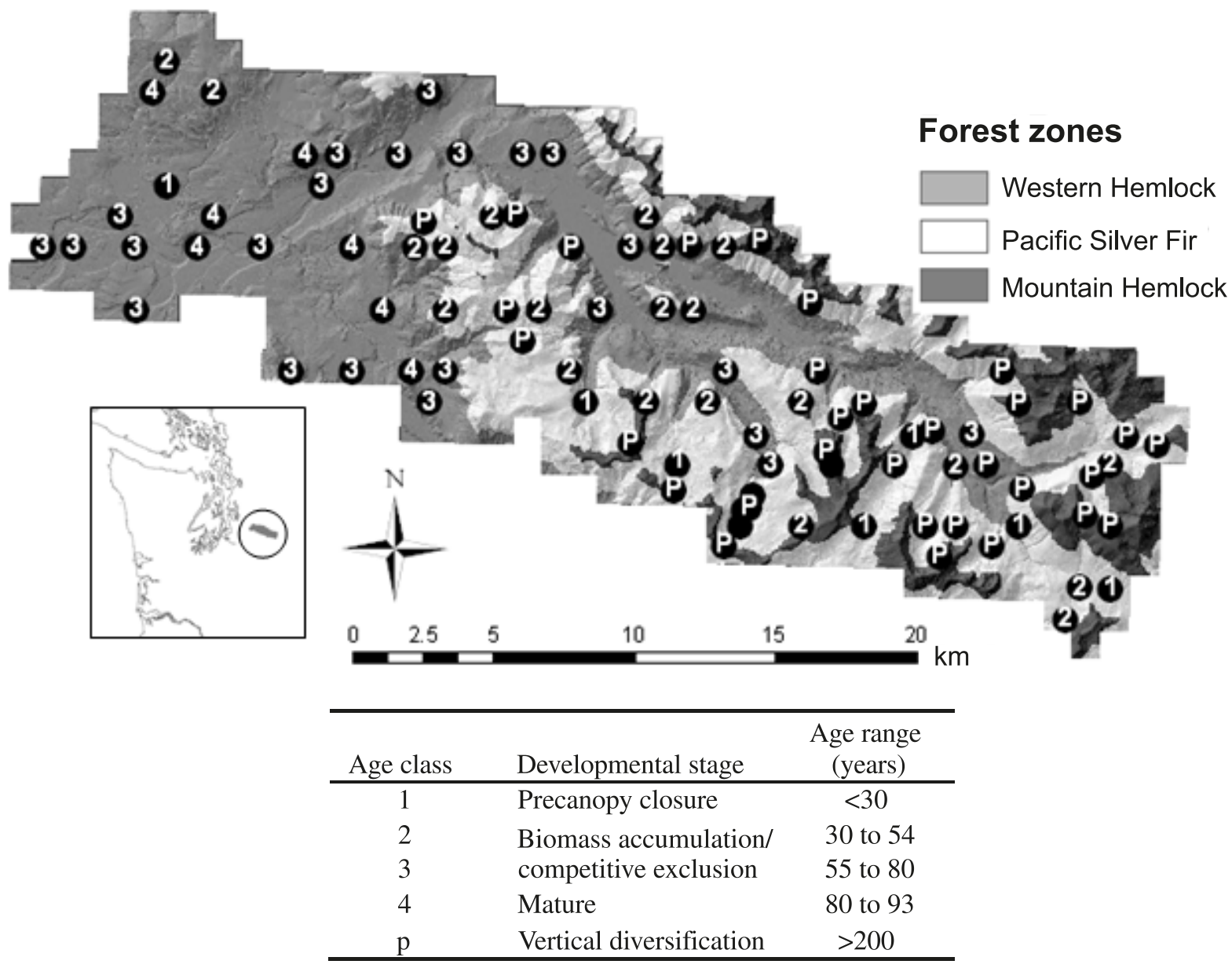

have regenerated following widespread stand-replacing disturbances, presumably fires (Hemstrom and Franklin 1982; J.A. Henderson (personal communication, 2009)). Forests in one basin survived the disturbances of 200-350 years ago and have a cohort of trees $\sim 600$ years old.

\section{Field data}

The watershed contains a network of 115 permanent sample plots laid out in an approximate grid designed to sample the range of forest types and environmental conditions within the watershed. Field data were collected between 2003 and 2005, with most sampling done in the summer and early fall. Twenty-one plots were eliminated from this study because of missing data or because deciduous trees comprised $>5 \%$ of the basal area. Of the 94 plots that were used in this study, 59 were second-growth and 35 were primary forests (Fig. 4).

The stand age for each plot site was estimated by coring dominant trees within the plot and assigning the age of the oldest trees to the site. All secondary forest sites were aged, and 17 of the 35 primary forest plots were aged. Forest ages were further verified with historic harvest and regeneration maps maintained by the Watershed's management.

Field plot radius was chosen to include $>25$ live trees with $\mathrm{DBH}>12.7 \mathrm{~cm}$. Plots ranged from 0.04 to 0.16 ha with a mean of 0.10 ha and a mode of 0.08 ha $59 \%$ of plots). The location of each plot center was determined using a Trimble Pathfinder Pro XRS GPS System and recorded on a TSC1 Asset Surveyor. The data were postprocessed using Trimble Pathfinder software to remove satellite position distortion.

Each tree was classified as dominant, codominant, intermediate, or overtopped (Smith et al. 1997). Only data from dominant, codominant, and intermediate trees were included in this study because these trees had crowns that would have been measured by the LiDAR instrument. Canopy cover was measured as the mean of 16 canopy closure measurements taken using a spherical densiometer at four points along each of four lines radiating from the plot center in each cardinal direction.

\section{LiDAR data}

LiDAR data were collected by Spectrum Mapping, LLC using their DATIS II system over the winter of 2002-2003. The nominal flying height above ground for the LiDAR acquisition was $2000 \mathrm{~m}$. The LiDAR data were collected using a laser pulse repetition rate of $35 \mathrm{kHz}$ and a scan rate of $25 \mathrm{~Hz}$ while being confined to a scan angle of $\pm 13.5^{\circ}$. These 
Fig. 4. Histograms showing study site characteristics for site age, plot size, LiDAR pulse density, and proportion of first returns out of all returns. Unaged sites are all primary forests believed to be 220-350 years old.
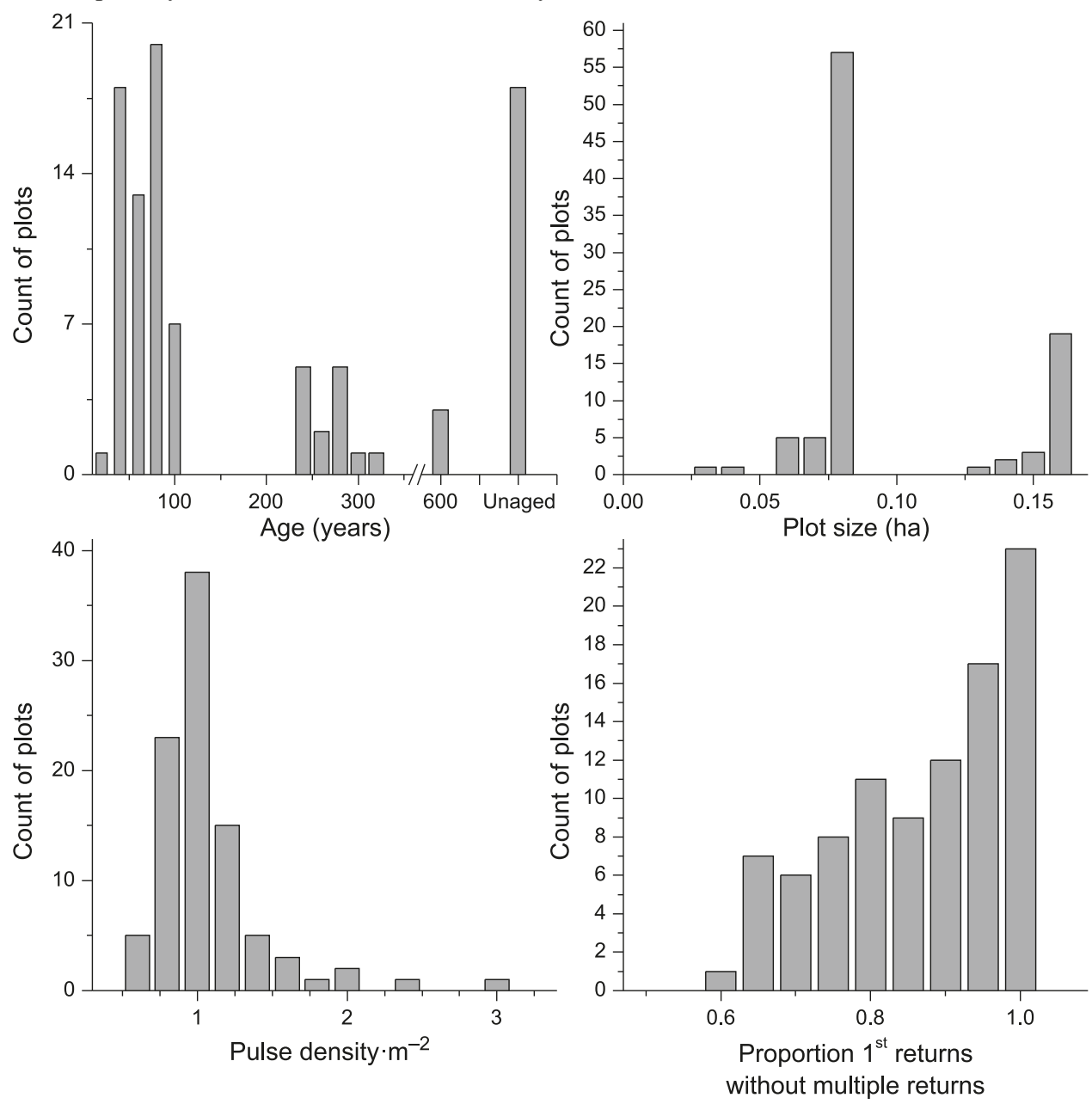

specifications resulted in a ground footprint diameter of $0.46 \mathrm{~m}$, with an average spacing of laser pulses of $1.0 \mathrm{~m}$ across track and $2.0 \mathrm{~m}$ along track. Up to five returns were recorded from each pulse. Swath centerline spacing was $400 \mathrm{~m}$ with an approximate overlap of $50 \%$ between adjacent flightlines.

Pulse (first return) point density for study plots ranged from 0.4 to $2.7 \mathrm{~m}^{-2}$ (mean $=0.97 \mathrm{~m}^{-2}$ ) among study plots (Fig. 4). The proportion of pulses without multiple returns ranged from 0.59 to 1.00 (mean $=0.85)$. To ensure that variation in the multiple return proportions did not affect results, only the three-dimensional positions of the first return LiDAR data were used for calculating canopy structure metrics. As a result, only trees with exposed crown surfaces were likely included in the LiDAR data.

LiDAR data were processed using the FUSION software package (beta version derived from version 2.64; http:// forsys.cfr.washington.edu/fusion.html). A digital terrain model was calculated for the entire watershed. All returns in the LiDAR point cloud were filtered to identify ground returns using an iterative algorithm (Kraus and Pfeifer 1998; Andersen et al. 2006) that computed an initial surface using the weighted average of all LiDAR returns. A cell size of $8 \mathrm{~m} \times 8 \mathrm{~m}$ was chosen for the initial and intermediate

surfaces to provide a sufficient number of ground points within each cell given the moderate density of the LiDAR data and the dense canopy present at many plot sites. For each iteration, weights were computed by comparing the return elevation with the elevation interpolated from the surface derived in the previous iteration or the initial surface for the first iteration. Points below the surface were given large weights and points above the surface were given a weight of zero. At the conclusion of each iteration, a new surface, presumably closer to the "true" ground surface, was computed. After the desired number of iterations, points on or below the final intermediate surface were identified as ground points. The algorithm requires that the user specify the number of iterations. For this study, five iterations were used to remove nonground returns.

Once a set of ground returns was identified, a digital terrain model covering the entire watershed was created using $3 \mathrm{~m} \times 3 \mathrm{~m}$ grid cells. If identified ground points were present in a cell, the cell was assigned the minimum value of those points. If no ground points were present in a cell, the ground elevation was interpolated using a "hole-filling" algorithm to search in eight adjacent directions for valid elevations and then compute the distance-weighted average of the valid elevations from surrounding cells. All canopy 
structural metrics were based on heights above the digital terrain model.

For each plot, LiDAR metrics were calculated for a sample of the LiDAR data the same size as the field plot and for a fixed $30 \mathrm{~m} \times 30 \mathrm{~m}(0.09 \mathrm{ha})$ area centered on the plot's GPS location. The $30 \mathrm{~m} \times 30 \mathrm{~m}$ size approximated the most common plot size and is characteristic of a grid cell size that might be used in a mapping effort. Canopy surface models were created for each study site from first returns using a $1.5 \mathrm{~m}$ grid cell and a $3 \times 3$ smoothing algorithm. These parameters were compromises that provided realistic canopies over the range of canopy types and pulse densities in the study. The $1.5 \mathrm{~m}$ cell size was chosen to ensure that most sites averaged at least one point per grid cell defining the canopy surface model height. Smoothing eliminated the jagged, unnatural canopy surface that is common when moderate-density LiDAR data are used without smoothing, such as "pits" within tree crowns due to small gaps that permit a first return from the ground surface.

\section{Statistical analysis}

Correlations between field and LiDAR metrics were compared both for individual metrics using Pearson coefficients and for multivariate sets of metrics using principal components analysis (PCA). PCA was appropriate for these data, as most variables had approximately linear relationships with each other (McCune and Grace 2002). Correlations were computed for both the fixed- and the variable-sized LiDAR samples. Plots were identified by age classes in ordinations.

We selected 10 combinations of field and LiDAR metrics for PCA and comparison. Three "base" combinations were used: one that included all 11 field and LiDAR metrics, one that used only the five field metrics, and one that used only the six LiDAR metrics. The remaining seven combinations were subsets of three metrics following the same pattern as Lefsky et al. (2005): a size measurement, a size variation measurement, and a cover measurement. One of these seven sets of three metrics used field metrics and the others used different combinations of LiDAR metrics.

Within the ordinations, PCA was conducted with the prcomp function of the $\mathrm{R}$ statistical package (release 2.6.1) (R Development Core Team 2007). All variables were normalized prior to analysis to eliminate differences in scale and units of measurement among variables. Separate ordinations were done for the LiDAR data that matched the size of each study site and for the fixed $30 \mathrm{~m} \times 30 \mathrm{~m}$ areas.

Procrustes analysis (Digby and Kempton 1987) was used to determine the correlation between pairs of ordinations. We were particularly interested in how well the information contained in ordinations of the base combinations could be represented by the subsets of LiDAR metrics. The Procrustes test rotates and rescales the axes of two ordinations and then computes the sum of squares error $\left(\mathrm{m}^{2}\right)$ between the locations of corresponding points in the two ordinations (Fig. 5). A correlation-like coefficient ( $r$ ) was computed as $r$ $=\operatorname{sqrt}\left(1-m^{2}\right)$ and significance $(p)$ was computed through permutations of the data. Statistical significance of the Procrustes tests was determined with the protest function in the vegan package (release 1.8-8) (Oksanen et al. 2008) of $R$ with 1000 permutations.
Fig. 5. Example of translation and rotation used in Procrustes analysis to calculate correlation between ordinations shown in Fig. $6 c$ and $6 d$. Segments connect the location of each site in ordination space based on the LiDAR core metrics (shaded circles) and the field core metrics (open circles). Rotation can be seen by comparing the horizontal and vertical axes of the ordination based on LiDAR core metrics (solid axes) and subset of field metrics (broken axes). The overall correlation between these ordinations was Procrustes $R=0.87(p<0.01)$.

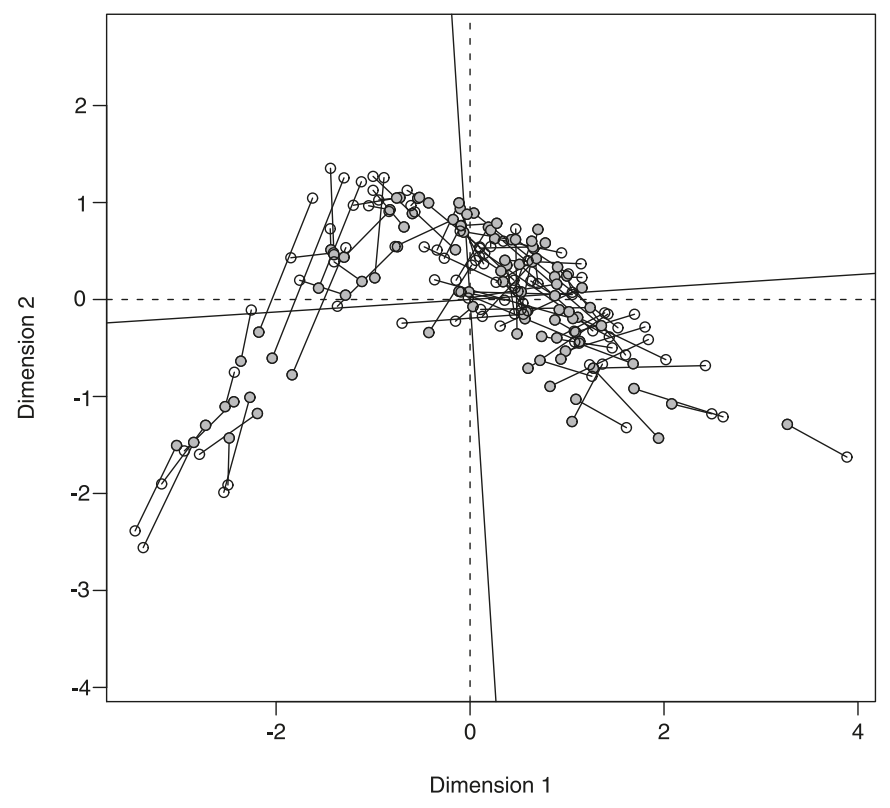

\section{Results}

Correlation between field- and LiDAR-based measures of structural complexity

\section{Individual metrics}

Most field and LiDAR metrics were correlated (Table 3). Canopy cover (a field measurement) and canopy density (a LiDAR measurement) were strongly correlated. Mean DBH, $\mathrm{SD}$ of $\mathrm{DBH}, \mathrm{SD}$ of height, and rumple were correlated. Mean and 95th percentile height formed another set of correlated metrics. On the other hand, tree density, large-tree $(>100 \mathrm{~cm} \mathrm{DBH})$ density, and $\mathrm{CV}$ of height had no significant correlations with many metrics and only weak correlations with others metrics.

\section{Ordinations}

Ordinations using different sets of metrics were found to explain similar amounts of variation and show similar relationships between sites (Fig. 6 shows four of the 10 ordinations performed). Because a substantial portion of the variance in all ordinations was explained in the first two axes, only these axes are presented and interpreted. The first two axes explained $71.3 \%$ of variations for the "all field and LiDAR" metrics ordination (Fig. 6a), 78.4\% for the "all field" ordination (Fig. 6b), and $83.0 \%$ for the "all LiDAR" ordination (not shown). In the first two of these ordinations, the variation explained in the first two axes was reduced because the density of trees $>100 \mathrm{~cm}$ DBH was loaded most strongly onto the third axis. The first two axes explained $87.7 \%-96.5 \%$ of the variation in ordinations based on sub- 
Table 3. Pearson correlations of LiDAR metrics with other LiDAR metrics and field metrics.

\begin{tabular}{|c|c|c|c|c|c|c|}
\hline & $\begin{array}{l}\text { 95th percentile } \\
\text { height }\end{array}$ & Mean height & Rumple & SD height & CV height & $\begin{array}{l}\text { Canopy } \\
\text { density }\end{array}$ \\
\hline \multicolumn{7}{|l|}{ Lidar metrics } \\
\hline 95th percentile height & 0.98 & & & & & \\
\hline Mean height & $0.94(0.94)$ & 0.96 & & & & \\
\hline Rumple & $0.76(0.63)$ & $0.51(0.38)$ & 0.90 & & & \\
\hline SD height & $0.80(0.68)$ & $0.57(0.43)$ & $0.94(0.88)$ & 0.91 & & \\
\hline CV height & & -0.23 & & & 0.94 & \\
\hline Canopy density & $0.65(0.62)$ & $0.73(0.69)$ & 0.26 & 0.31 & -0.24 & 0.93 \\
\hline \multicolumn{7}{|l|}{ Field metrics } \\
\hline Density of canopy trees & & & $-0.42(-0.33)$ & $-0.38(-0.37)$ & & $0.34(0.31)$ \\
\hline Density of trees $>100 \mathrm{~cm} \mathrm{DBH}$ & $0.34(0.28)$ & & $0.44(0.40)$ & $0.41(0.33)$ & & \\
\hline Mean DBH & $0.83(0.80)$ & $0.67(0.67)$ & $0.76(0.62)$ & $0.83(0.75)$ & & $0.39(0.35)$ \\
\hline SD DBH & $0.74(0.67)$ & $0.53(0.50)$ & $0.80(0.73)$ & $0.78(0.70)$ & & $0.35(0.32)$ \\
\hline Canopy cover & $0.55(0.53)$ & $0.56(0.53)$ & $0.304(0.271)$ & $0.38(0.31)$ & & $0.71(0.64)$ \\
\hline
\end{tabular}

sets of field (Fig. 6c) and LiDAR (Fig. 6d) metrics. In each ordination, the first principal component was primarily correlated with measures of size (DBH or height) and size variation. The second principal component was primarily correlated with measures of canopy closure/density and (or) tree density.

Each ordination showed a distinct V-shaped pattern. The arms of the " $V$ " were labeled based on the characteristics of the sites present. In each ordination, one arm had sites $<50$ years old predominating, a trend of increasing height and canopy density, and was labeled ">Closure". The other arm had sites $>75$ years old predominating, a trend of increasing rumple and decreasing canopy density, and was labeled ">Complexity". Sites 50-75 years old were predominant at the base of the "V".

\section{Effect of using different subsets of LiDAR metrics}

Ordinations using different sets of metrics generally were correlated, and two subsets of LiDAR metrics were found that were highly correlated with the full set of field and LiDAR metrics and the sets of field metrics. With the exception of ordinations that included CV of height, ordinations had Procrustes correlations of 0.71-0.96 (Table 4). Ordinations that included CV of height had correlations of $0.40-$ 0.87. Ordinations with subsets of three LiDAR metrics that did not include CV of height had similar correlations with the " "all field and LiDAR", "all field", and "field subset" ordinations. The ordination produced with the LiDAR 95th percentile of height, rumple, and canopy density had slightly higher correlations with "all field and LiDAR" and "all field" ordinations than other tested subsets of LiDAR metrics. An ordination that substituted SD of height for rumple had a marginally higher correlation with the "field subset" ordination.

\section{Effect of LiDAR sample area}

In almost every case, Pearson correlations were higher for the fixed-sized LiDAR sample than for the variable-sized LiDAR sample that matched the plot size (Table 3). Correlations between ordinations using subsets of LiDAR metrics and field metrics were higher when the fixed $30 \mathrm{~m} \times 30 \mathrm{~m}$ LiDAR plots were used than when the variable-sized LiDAR samples were used that matched the size of the underlying field plot (Table 4). Variable-sized plot sites produced higher correlations between subsets of LiDAR metrics and the full set of LiDAR metrics.

\section{Discussion}

\section{Correlation between field- and LiDAR-based measures of} structural complexity

The high correlation between field and LiDAR metrics and ordinations in our study indicates that these two sets of measurements captured similar patterns in stand structure. Our findings, therefore, support the use of LiDAR measurements to directly map forest structural complexity and infer age-related successional stage (as was done in Kane et al. 2010).

The changes in the field and LiDAR ordinations appear to correspond to key changes in structure for Pacific Northwest forests (Spies and Franklin 1991; Franklin et al. 2002). In the ordinations, the arm labeled ">Closure" appears to represent the processes of canopy closure and mortality typical of the biomass accumulation/competitive exclusion stages. The other arm labeled ">Complexity" appears to represent the increase of structural heterogeneity, canopy layering, and the creation of canopy gaps typical of the maturation and vertical diversification stages. The strong pattern in the ordinations suggests that the field and LiDAR metrics correlate well with dominant processes in forest structural development.

Authors who have studied the development of forest structure have emphasized that the process is highly variable, with some sites developing advanced structural characteristics more quickly than others (Franklin et al. 2002; Larson et al. 2008). This was evident in the arm of our ordinations representing the accumulation of greater complexity following canopy closure. Younger sites were more common at the base of this arm and only primary sites were found at its end, but considerable mixing of site ages occurred in be- 
Fig. 6. Ordinations resulting from principal components analyses of different sets of field and LiDAR metrics using fixed-sized LiDAR sample areas. LiDAR density is the canopy density computed from LiDAR data. Plots shown by age classes based on development stages from Franklin et al. (2002) based on typical ages for the Western Hemlock Zone. The length of each arrow indicates the strength of the correlation between that variable and the axes. Angles between arrows indicate the strength of the correlation between the metrics (smaller angles $<90^{\circ}$ indicate higher positive correlations, $90^{\circ}$ angles are uncorrelated, $>90^{\circ}$ angles are negatively correlated, and $180^{\circ}$ angles are perfectly negatively correlated). The bottom and left axes (coordinate system 1) are the principal components (actual observations matrix multiplied by loadings), while the top and right axes (coordinate system 2) are the loadings ("weights" assigned to each variable after centering and scaling).
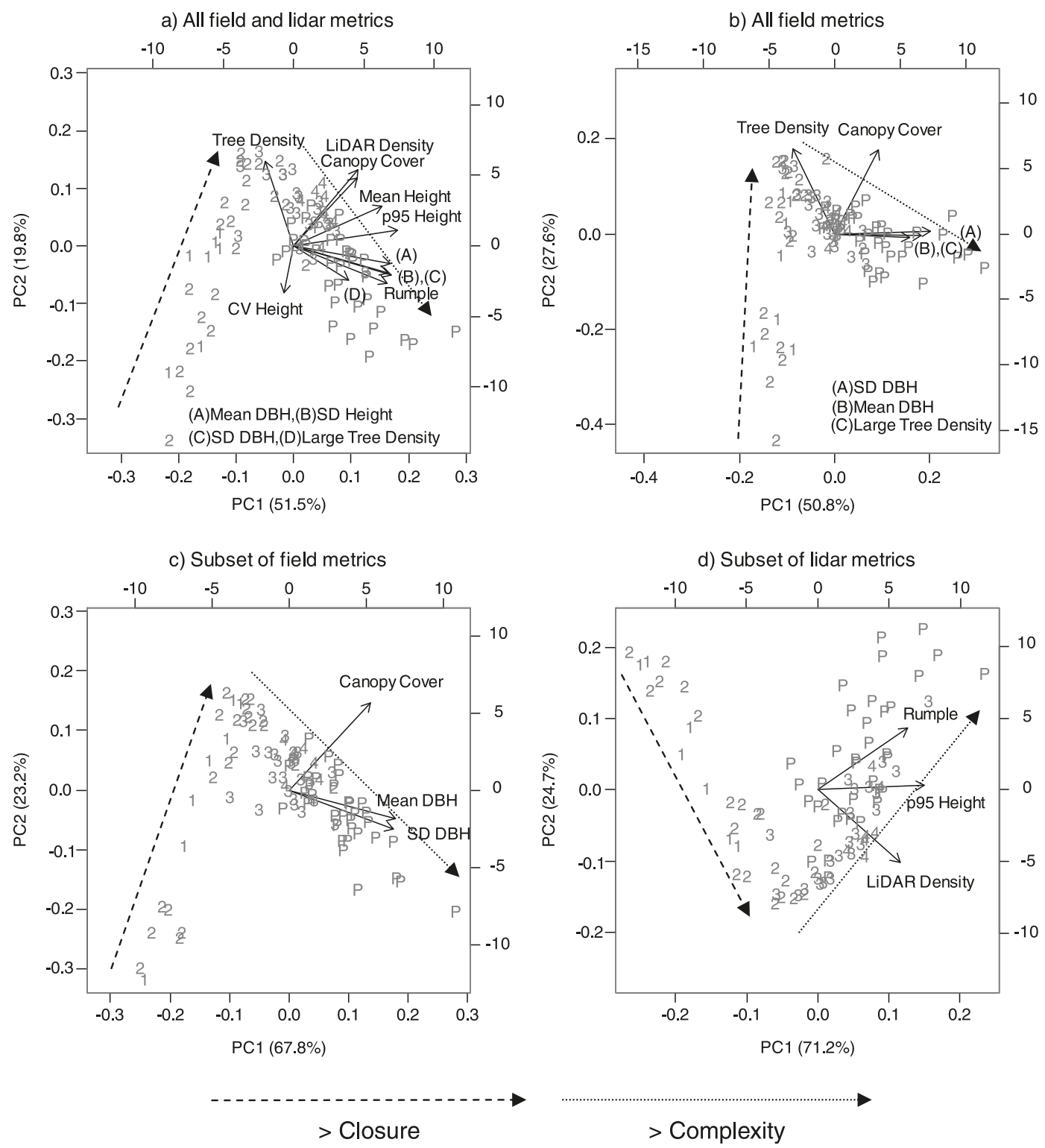

\begin{tabular}{clc}
\hline Age class & Developmental stage & $\begin{array}{c}\text { Age range } \\
\text { (years) }\end{array}$ \\
\hline 1 & Precanopy closure & $<30$ \\
2 & Biomass accumulation/ & 30 to 54 \\
3 & competitive exclusion & 55 to 80 \\
4 & Mature & 80 to 93 \\
p & Vertical diversification & $>200$ \\
\hline
\end{tabular}

tween. Many second-growth sites had more structural complexity (whether measured with field or LiDAR metrics) than many primary sites, perhaps because of establishment histories (Tappeiner et al. 1997; Winter et al. 2002) or a history of intermediate disturbance (Zenner 2005; Lutz and Halpern 2006). The causes and implications of variations in 


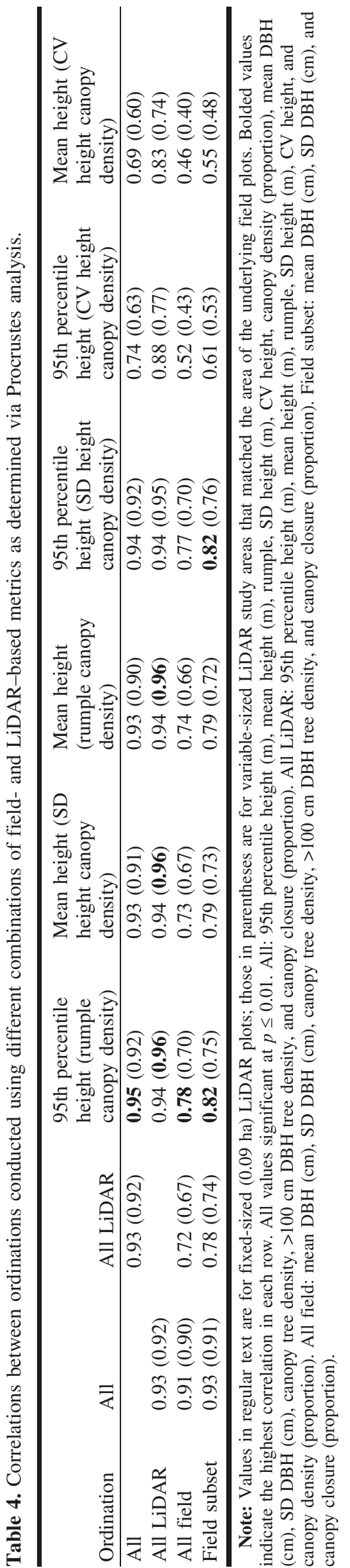

stand development shown in these ordinations are more fully explored in a companion paper (Kane et al. 2010).

Our study had limitations for studying structural development of Pacific Northwest forests because of the lack of sites in the 94- to 222-year-old and 351- to 599-year-old age ranges. These data gaps may reduce the ability to extrapolate our results to conifer forests of all age ranges. However, the lack of gaps in the ordinations suggests that our data set captured dominant processes that drive the development of structural complexity. Future LiDAR acquisitions that include larger wider ranges of stand ages can test this assertion and extend our results. These results should also be tested using other forest types.

The arch present in the PCA ordinations was not a mathematical artifact as can occur with community data (Podani and Miklos 2002). It was also present in nonmetric multidimensional scaling ordinations (not shown), indicating that it was an inherent characteristic of the data set. The arch structure was also seen in the ordinations of structural metrics performed by Spies and Franklin (1991) and Lefsky et al. (2005).

The arch itself corresponds to changing dominance of key processes during stand development (Franklin et al. 2002). Canopy closure increases early in stand development but the canopy then partially reopens through gap formation. Tree density decreases through competition mortality and disturbance and then increases because of the emergence of trees from the understory. Structural heterogeneity of the canopy surface (rumple) remains relatively low early in stand development but begins to increase as vertical and horizontal diversification of the canopy surface develops.

\section{Selection of a subset of metrics}

Lefsky et al. (2005) found that stand structure can be characterized using three categories of LiDAR metrics: one to represent biomass (height measurement), one to measure canopy structural complexity (variability of height), and one to measure canopy gaps and leaf area index (canopy density) (Lefsky et al. 2005). We found that subsets that included one LiDAR metric from each of these categories correlated with sets of metrics that included field data better than did the full suite of LiDAR metrics. Hence, we may reduce redundancy of these measures to an intuitive subset of LiDAR metrics to describe stand structure.

We used 95th percentile height as our measure of stand height (Lefsky et al. 2005). This metric was loaded most strongly on the first principal component (Fig. 6d). Individual metrics to represent height were highly correlated, suggesting that the choice of particular metrics probably made little difference to the conclusions. Nonetheless, we suggest that 95th percentile height is preferable to mean height because of the pattern of crown development for trees in our region. While foliage distribution in young conifer stands is generally concentrated in the top canopy layers and crowns are relatively short, foliage is more evenly distributed throughout the canopy space in older stands due to greater light penetration (Ishii and McDowell 2002; Van Pelt and Sillett 2008). Mean height of LiDAR returns, therefore, would reflect the combination of tree height growth and foliage redistribution, making interpretation of results problematic. In addition, the 95th percentile height metric is less 
sensitive to outliers than metrics such as maximum height, which was not tested because it can be skewed by a small portion of the area with abnormally high material or even by returns from flying birds.

Rumple, our metric for canopy structural complexity, generally had higher values for older plots, consistent with theories of canopy development for many forests (Ishii et al. 2004) but possibly not for forests with periodic large-scale disturbances (Brokaw et al. 2004). This study tested two alternatives to rumple, $\mathrm{SD}$ of height and $\mathrm{CV}$, as a measure of spatial heterogeneity. We found that $\mathrm{CV}$ produced weaker correlations with field metric ordinations and that rumple generally had slightly higher correlations than SD. Lefsky et al. (2005) used SD of height but could not have calculated rumple from their large-footprint, waveform LiDAR data. We prefer rumple because it is sensitive to the threedimensional arrangement of canopy material (Fig. 2). Rumple is correlated with a number of measures of stand structural complexity (Kane et al. 2008) and increases with stand age (Ogunjemiyo et al. 2005). Work by Zenner (2004) also supports the selection of rumple. He demonstrated that stands with similar measurements of tree diameter and count could have very different spatial arrangements of trees due to differences in disturbance histories. These stands would presumably also have different spatial arrangements of canopy material. We suggest that a metric sensitive to the threedimensional arrangement of the canopy surface may be a more sensitive detector of past disturbance than a one-dimensional metric such as SD. However, our field data did not allow us to determine whether rumple was detecting structural complexity that SD of height would not. A goal for future research would be to determine how rumple measurements are correlated with spatial patterns in tree and crown distributions.

We used canopy density as our metric of gaps and canopy continuity. Canopy density rapidly increased with age for young plots, remained at high values for most secondary sites >35 years, and declined modestly for primary sites; these dynamics were consistent with both the field data for canopy closure and the theories of canopy development (Van Pelt and Franklin 2000; Van Pelt and Nadkarni 2004).

\section{Effect of size of LiDAR sample area}

A surprising result from our study was that correlations between field- and LiDAR-based ordinations generally were lower when based on variable-sized LiDAR study areas than when based on fixed 0.09 ha study areas. The fixed-size study areas were larger than most second-growth sites but smaller than most primary forest sites. These differences suggest that there may be an optimal sample area size for characterizing forests from LiDAR canopy data. This is an avenue for further study; researchers might explore different-sized areas for measuring LiDAR data to determine if there is an optimal size for their forest types.

\section{Conclusions}

The cost of traditional field measurements limits the amount of forest structural data that can be collected. We developed methods for measuring the structural complexity of closed-canopy conifer forests using simple LiDAR metrics that were strongly correlated with structure as measured through field metrics of live trees. Future studies that coordinate field and LiDAR measurements might seek to better understand the relationship between the processes acting on tree stems and canopies.

The low cost of LiDAR acquisition (on a per hectare basis) opens up new opportunities to measure and study forest structure at stand to landscape scales. These data would provide forest ecologists and managers with data from the equivalent area of hundreds of thousands of field plots. Data sets representing large spatial scales combined with field data would permit in-depth explorations of forest development across different age ranges, geomorphologies, and spatial scales to explore variation in the paths along which structural complexity develops.

This study supports Lefsky et al.'s (2005) conclusion that forest structure can be characterized with a small set of core LiDAR metrics with high correlation with field metrics. We also found that LiDAR metrics retain their correlation when the size of the LiDAR sample area differs from the size of the field plot. The specific metrics and LiDAR samples that best describe canopy structural complexity may differ among forest biomes, but we believe that identifying core sets of easily interpreted LiDAR metrics will make LiDAR data more usable by a wide range of ecologists and forest professionals.

\section{Acknowledgements}

This work was supported by NASA Headquarters under the NASA Earth and Space Science Fellowship Program (grant NNX07AN75H). The Watershed Services Division of Seattle Public Utilities, the King County Government of Washington State, and the Nature Conservancy of Washington State provided funding support. The Watershed Services Division of Seattle Public Utilities shared their permanent plot and LiDAR data used in the study. Comments by Derek Churchill, James A. Freund, R. Keala Hagmann, Charles Halpern, Andrew J. Larson, and Christian Torgersen improved earlier drafts of this article. We thank two anonymous reviewers for their suggestions.

\section{References}

Acker, S.A., Sabin, T.E., Ganio, L.M., and McKee, W.A. 1998. Development of old-growth structure and timber volume growth trends in maturing Douglas-fir stands. For. Ecol. Manag. 104(13): 265-280. doi:10.1016/S0378-1127(97)00249-1.

Andersen, H.E., Reutebuch, S.E., and McGaughey, R.J. 2006. A rigorous assessment of tree height measurements obtained using airborne lidar and conventional field methods. Can. J. Remote Sens. 32(5): 355-366.

Brokaw, N., Fraver, S., Grear, J.S., Thompson, J., Zimmerman, J.K., Waide, R.B., Everham, E.M., III, Hubbell, S.P., and Foster, R.B. 2004. Disturbance and canopy structure in two tropical forests. In Tropical forest diversity and dynamism - findings from a large-scale plot network. Edited by E.C. Losos and E.G. Leigh Jr. University of Chicago Press, Chicago, Ill. pp. 177-194.

Digby, P.G.N., and Kempton, R.A. 1987. Multivariate analysis of ecological communities. Chapman and Hall, London, U.K.

Erckmann, J., Chinn, A., Flagor, S., Kurko, K., Freeman, J., Little, R., Schneider, G., and Vanderhoof, J. 2000. Final Cedar River Watershed Habitat Conservation Plan. City of Seattle, Wash. Available from www.seattle.gov/util/About_SPU/Water_System/ Habitat_Conservation_Plan/AbouttheHCP/Documents/index.htm. 
Falkowski, M.J., Evans, J.S., Martinuzzi, S., Gessler, P.E., and Hudak, A.T. 2009. Characterizing forest succession with lidar data: an evaluation for the Inland Northwest, USA. Remote Sens. Environ. 113(5): 946-956. doi:10.1016/j.rse.2009.01.003.

Franklin, J.F., and Dyrness, C.T. 1988. Natural vegetation of Oregon and Washington. Oregon State University Press, Corvallis, Ore.

Franklin, J.F., and Spies, T.A. 1991. Composition, function, and structure of old-growth Douglas-fir forests. In Wildlife and vegetation of unmanaged Douglas-fir forests. Edited by L.F. Ruggiero, K.B. Aubry, A.B. Carey, and M.H. Huff. U.S. For. Serv. Gen. Tech. Rep. PNW-GTR-285. pp. 71-80.

Franklin, J.F., Spies, T.A., Van Pelt, R., Carey, A.B., Thornburgh, D.A., Berg, D.R., Lindenmayer, D.B., Harmon, M.E., Keeton, W.S., Shaw, D.C., Bible, K., and Chen, J.Q. 2002. Disturbances and structural development of natural forest ecosystems with silvicultural implications, using Douglas-fir forests as an example. For. Ecol. Manag. 155(1-3): 399-423. doi:10.1016/S03781127(01)00575-8.

Harding, D.J., Lefsky, M.A., Parker, G.G., and Blair, J.B. 2001. Laser altimeter canopy height profiles - methods and validation for closed-canopy, broadleaf forests. Remote Sens. Environ. 76(3): 283-297. doi:10.1016/S0034-4257(00)00210-8.

Hemstrom, M.A., and Franklin, J.F. 1982. Fire and other disturbances of the forests in Mount Rainier National Park. Quat. Res. 18(1): 32-51. doi:10.1016/0033-5894(82)90020-5.

Henderson, J.A., Lesher, R.D., Peter, D.H., and Shaw, D.C. 1992. Field guide to the forested plant associations of the Mt. BakerSnoqualmie National Forest. Tech. Pap. R6. ECOL TP 028-91. U.S. Department of Agriculture Forest Service, Pacific Northwest Research Station

Hill, R.A., and Thomson, A.G. 2005. Mapping woodland species composition and structure using airborne spectral and LiDAR data. Int. J. Remote Sens. 26(17): 3763-3779. doi:10.1080/ 01431160500114706.

Ishii, H., and McDowell, N. 2002. Age-related development of crown structure in coastal Douglas-fir trees. For. Ecol. Manag. 169(3): 257-270. doi:10.1016/S0378-1127(01)00751-4.

Ishii, H.T., Van Pelt, R., Parker, G.G., and Nadkarni, N.M. 2004. Age-related development of canopy structure and its ecological functions. In Forest canopies. Edited by M.D. Lowman and H.B. Rinker. Elsevier Academic Press, Burlington, Mass.

Kane, V.R., Gillespie, A.R., McGaughey, R., Lutz, J.A., Ceder, K., and Franklin, J.F. 2008. Interpretation and topographic compensation of conifer canopy self-shadowing. Remote Sens. Environ. 112(10): 3820-3832. doi:10.1016/j.rse.2008.06.001.

Kane, V.R., Bakker, J.D., McGaughey, R.J., Lutz, J.A., Gersonde, R.F., and Franklin, J.F. 2010. Examining conifer canopy structural complexity across forest ages and elevations with LiDAR data. Can. J. For. Res. 40(4): 774-787. doi:10.1139/X10-064.

Kraus, K., and Pfeifer, N. 1998. Determination of terrain models in wooded areas with airborne laser scanner data. ISPRS J. Photogramm. Remote Sens. 53(4): 193-203. doi:10.1016/S09242716(98)00009-4.

Larson, A.J., Lutz, J.A., Gersonde, R.F., Franklin, J.F., and Hietpas, F.F. 2008. Potential site productivity influences the rate of forest structural development. Ecol. Appl. 18(4): 899-910. doi:10. 1890/07-1191.1. PMID:18536251.

Larson, J.A., and Franklin, F.J. 2006. Structural segregation and scales of spatial dependency in Abies amabilis forests. J. Veg. Sci. 17(4): 489-498.

Lefsky, M.A., Cohen, W.B., Acker, S.A., Parker, G.G., Spies, T.A., and Harding, D. 1999. Lidar remote sensing of the canopy structure and biophysical properties of Douglas-fir western hemlock forests. Remote Sens. Environ. 70(3): 339-361. doi:10.1016/ S0034-4257(99)00052-8.

Lefsky, M.A., Cohen, W.B., and Spies, T.A. 2001. An evaluation of alternate remote sensing products for forest inventory, monitoring, and mapping of Douglas-fir forests in western Oregon. Can. J. For. Res. 31(1): 78-87. doi:10.1139/cjfr-31-1-78.

Lefsky, M.A., Cohen, W.B., Harding, D.J., Parker, G.G., Acker, S.A., and Gower, S.T. 2002. Lidar remote sensing of aboveground biomass in three biomes. Glob. Ecol. Biogeogr. 11(5): 393-399. doi:10.1046/j.1466-822x.2002.00303.x.

Lefsky, M.A., Hudak, A.T., Cohen, W.B., and Acker, S.A. 2005. Patterns of covariance between forest stand and canopy structure in the Pacific Northwest. Remote Sens. Environ. 95(4): 517531. doi:10.1016/j.rse.2005.01.004.

Lertzman, K.P., and Krebs, C.J. 1991. Gap-phase structure of a sub-alpine old-growth forest. Can. J. For. Res. 21(12): 17301741. doi:10.1139/x91-239.

Lindenmayer, D.B., and Franklin, J.F. 2002. Conserving forest biodiversity: a comprehensive multiscaled approach. Island Press, Washington, D.C.

Lutz, J.A., and Halpern, C.B. 2006. Tree mortality during early forest development: a long-term study of rates, causes, and consequences. Ecol. Monogr. 76(2): 257-275. doi:10.1890/00129615(2006)076[0257:TMDEFD]2.0.CO;2.

McCune, B., and Grace, J.B. 2002. Analysis of ecological communities. MjM Software Design, Gleneden Beach, Ore.

McElhinny, C., Gibbons, P., Brack, C., and Bauhus, J. 2005. Forest and woodland stand structural complexity: its definition and measurement. For. Ecol. Manag. 218(1-3): 1-24. doi:10.1016/j. foreco.2005.08.034.

Næsset, E., and Okland, T. 2002. Estimating tree height and tree crown properties using airborne scanning laser in a boreal nature reserve. Remote Sens. Environ. 79(1): 105-115. doi:10.1016/ S0034-4257(01)00243-7.

Ogunjemiyo, S., Parker, G., and Roberts, D. 2005. Reflections in bumpy terrain: Implications of canopy surface variations for the radiation balance of vegetation. IEEE Geosci. Remote Sens. Lett. 2(1): 90-93. doi:10.1109/LGRS.2004.841418.

Oksanen, J., Kindt, R., Legendre, P., O’Hara, B., Simpson, G.L., Henry, M., Stevens, H., and Wagner, H. 2008. Vegan: community ecology package. R package version 1.13-1. Available from http://r-forge.r-project.org/projects/vegan.

Packee, E.C., Oliver, C.D., and Crawford, P.D. (Editors). 1982. Ecology of Pacific silver fir. Institute of Forest Resources Contribution No. 45. College of Forest Resources, University of Washington, Seattle, Wash.

Parish, R., and Antos, J.A. 2006. Slow growth, long-lived trees, and minimal disturbance characterize the dynamics of an ancient, montane forest in coastal British Columbia. Can. J. For. Res. 36(11): 2826-2838. doi:10.1139/X06-166.

Parker, G.G., and Russ, M.E. 2004. The canopy surface and stand development: assessing forest canopy structure and complexity with near-surface altimetry. For. Ecol. Manag. 189(1-3): 307315. doi:10.1016/j.foreco.2003.09.001.

Parker, G.G., Harmon, M.E., Lefsky, M.A., Chen, J., Van Pelt, R., Weis, S.B., Thomas, S.C., Winner, W.E., Shaw, D.C., and Franklin, J.F. 2004. Three-dimensional structure of an oldgrowth Pseudotsuga-Tsuga canopy and its implications for radiation balance, microclimate, and gas exchange. Ecosystems (N.Y., Print), 7(5): 440-453. doi:10.1007/s10021-004-0136-5.

Podani, J., and Miklos, I. 2002. Resemblance coefficients and the horseshoe effect in principal coordinates analysis. Ecology, 83(12): 3331-3343. doi:10.1890/0012-9658(2002)083[3331:RCATHE]2.0. $\mathrm{CO} ; 2$. 
R Development Core Team. 2007. R: a language and environment for statistical computing. Available from http://www.R-project. org.

Skowronski, N., Clark, K., Nelson, R., Hom, J., and Patterson, M. 2007. Remotely sensed measurements of forest structure and fuel loads in the Pinelands of New Jersey. Remote Sens. Environ. 108(2): 123-129. doi:10.1016/j.rse.2006.09.032.

Smith, D.M., Larson, B.C., Kelty, M.J., and Ashton, P.M.S. 1997. The practice of silviculture: applied forest ecology. John Wiley \& Sons, New York.

Spies, T.A. 1998. Forest structure: a key to the ecosystem. Northwest Sci. 72: 34-39.

Spies, T.A., and Franklin, J.F. 1991. The structure of natural young, mature, and old-growth Douglas-fir forests in Oregon and Washington. In Wildlife and vegetation of unmanaged Douglas-fir forests. Edited by L.F. Ruggiero, K.B. Aubry, A.B. Carey, and M.H. Huff. U.S. For. Serv. Gen. Tech. Rep. PNWGTR-285. pp. 91-109.

Tappeiner, J.C., Huffman, D., Marshall, D., Spies, T.A., and Bailey, J.D. 1997. Density, ages, and growth rates in old-growth and young-growth forests in coastal Oregon. Can. J. For. Res. 27(5): 638-648. doi:10.1139/cjfr-27-5-638.
Van Pelt, R., and Franklin, J.F. 2000. Influence of canopy structure on the understory environment in tall, old-growth, conifer forests. Can. J. For. Res. 30(8): 1231-1245. doi:10.1139/cjfr-30-81231.

Van Pelt, R., and Nadkarni, N.M. 2004. Development of canopy structure in Pseudotsuga menziesii forests in the southern Washington Cascades. For. Sci. 50(3): 326-341.

Van Pelt, R., and Sillett, S.C. 2008. Crown development of coastal Pseudotsuga menziesii, including a conceptual model for tall conifers. Ecol. Monogr. 78(2): 283-311. doi:10.1890/07-0158.1.

Winter, L.E., Brubaker, L.B., Franklin, J.F., Miller, E.A., and DeWitt, D.Q. 2002. Initiation of an old-growth Douglas-fir stand in the Pacific Northwest: a reconstruction from tree-ring records. Can. J. For. Res. 32(6): 1039-1056. doi:10.1139/x02031.

Zenner, E.K. 2004. Does old-growth condition imply high live-tree structural complexity? For. Ecol. Manag. 195(1-2): 243-258. doi:10.1016/j.foreco.2004.03.026.

Zenner, E.K. 2005. Development of tree size distributions in Douglas-fir forests under differing disturbance regimes. Ecol. Appl. 15(2): 701-714. doi:10.1890/04-0150. 